\title{
СОВЕРШЕНСТВОВАНИЕ СИСТЕМЫ ЦИФРОВОЙ МАРКИРОВКИ И ПРОСЛЕЖИВАЕМОСТИ ТОВАРОВ НА ПРИМЕРЕ ШОКОЛАДА
}

\section{IMPROVING THE SYSTEM OF DIGITAL LABELING AND TRACEABILITY OF CHOCOLATE}

\section{A. Petrosyan}

Summary. This paper considers the improvement the system of digital labeling and traceability of chocolate. A comparative analysis of the mandatory attributes presented in the catalog of labeled products, is carried out using implemented labeling system. Based on the analysis of the results of the implementation of the system digital labeling and the traceability of products, as well as the observed issues and trends in the market of raw materials for the production of chocolate (cocoa beans and cocoa butter) and finished products, the author proposed a list of general and specific attributes, that must be presented in the catalog of labeled products. Specific examples of indicating general and specific attributes for chocolate and compound chocolate bar (other products) are given.

Keywords: digital labeling, system of product traceability, product quality, consumer properties, product attributes, chocolate, cocoa butter substitutes.
B современном мире информационным технологиям и цифровизации уделяется особое внимание.

Одним из национальных информационных продуктов, который был разработан в рамках цифровых технологий в 2016 году и координируется Минпромторгом России, является система прослеживаемости товаров, предусматривающая обязательное цифровое маркирование товаров средствами идентификации. Применение данного механизма в отношении определенных категорий товаров уже доказало свою эффективность. Преимуществом системы является то, что она способствует повышению конкурентоспособности добросовестных участников рынка за счет сокращения доли незаконного оборота товаров, повышению собираемости таможенных и налоговых платежей, обеспечению защиты жизни и здоровья граждан, а также защиты их прав.

К 2024 году планируется применить систему маркирования ко всем группам товаров. В рамках продовольственных товаров первый объект эксперимен-
Петросян Анна Эдиковна

Аспирант, м.н.с., Российская таможенная академия talismananna96@mail.ru

Аннотация. В данной статье рассматриваются пути совершенствования системы цифровой маркировки и прослеживаемости товаров на примере шоколада на основе существующей системы. Проводится сравнительный анализ обязательных к заполнению атрибутов, представленных в каталоге маркированного товара, на примере уже внедренной системы маркировки в отношении предметов одежды из натурального меха, обувных товаров и лекарственных препаратов. На основе анализа результатов внедрения системы цифровой маркировки и прослеживаемости товаров, а также наблюдаемых проблемах и тенденциях на рынке исходного сырья для производства шоколада (какао-бобов и какао-масла) и готовой продукции автором предложен перечень общих и специфических атрибутов, обязательных к представлению в каталоге маркированного товара в случае распространения системы цифровой маркировки и прослеживаемости товаров в отношении шоколада. Приводятся конкретные примеры указания общих и специфических атрибутов для шоколада и кондитерской плитки (иных изделий).

Ключевые слова: цифровая маркировка, система прослеживаемости товаров, качество товара, потребительские свойства, атрибуты товара, шоколад, заменители какао-масла.

та - молоко и молочная продукция (сроки введения обязательной маркировки - 20 января 2021 г.- 1 октября 2021 г.) [1].

В рамках данной статьи разработан и предложен перечень общих и специфических атрибутов, обязательных к представлению в каталоге маркированного товара в рамках системы цифровой маркировки и прослеживаемости товаров, в отношении такого вида кондитерских изделий как шоколад, выделенных на основе анализа его свойств и характеристик.

Выбор данного вида продукции для анализа обусловлен высокими темпами его диверсификации, изменениями качества используемого исходного сырья и технологии производства, что приводит к производству готовой продукции с различным уровнем потребительских свойств, в т.ч. стоимостью.

Основным исходным сырьем для производства шоколада являются какао-бобы и какао-масло. В настоящее время на рынке лидирующих стран-экспортеров данного сырья (страны Африки - Кот-д'Ивуар, Гвинея, 
Гана и Либерия), на которых приходится 70\% всего мирового производства какао-бобов, наблюдаются отрицательные тенденции. Засуха, старение и заболевание какао-деревьев и, следовательно, снижение их способности к урожайности [2] влекут за собой дефицит сырья и увеличение его стоимости.

Ситуация на мировом рынке какао-бобов и какао-масла осложняется ростом мирового спроса на какао-бобы с каждым годом, особенно в азиатских странах. Кроме этого, ситуация обостряется за счет все более активного использования производителями в составе шоколада заменителей какао-сырья, в т.ч. таких «альтернативных» видов как пальмовое масло и его производные, рапсовое, кокосовое, масло ши и др., которые по своей стоимости и потребительским свойствам значительно уступают какао-маслу. По данным исследований некоторых ученых [3; 4] потребление пальмового масла и его производных, которые являются наиболее популярными при изготовлении шоколада видами растительных масел, наносит вред здоровью человека и отрицательно влияет на продолжительность его жизни.

Актуальность темы данной работы также подтверждается проведенным анализом ассортимента шоколада, реализуемого в магазинах розничной торговли, который показал, что на российской рынке присутствуют импортные образцы с нарушением требований технического регламента Евразийского экономического союза 022/2011 «Пищевая продукция в части ее маркировки» [5]. В основном отмечалось несоответствие видового наименования товара фактическому составу продукции и отсутствие информации о виде (видах) используемого (используемых) в продукте заменителя (заменителей) какао-масла и иных видах растительных масел.

Недостоверные сведения, указанные в т.ч. в маркировке товара, вводят в заблуждение потребителя о свойствах продукции и ее качестве. Особое значение имеет видовое наименование продукции, так как при выборе товара потребитель в первую очередь обращает внимание именно на него, а не на состав продукции.

Более того, выявлены случаи реализации в Российской Федерации продукции известного мирового бренда уровнем качества ниже, чем у аналогичного продукта, реализуемого на европейском рынке. В качестве примера можно привести возбужденное Федеральной антимонопольной службой в августе 2020 года дело о несоответствии содержания органических кислот (качественного признака) в шоколаде марки «Lindt», доступном к приобретению в России, и в образцах, приобретенных в Европе [6]. Это свидетельствует о том, что политика международных компаний в области внешней торговли данным видом продукции, подразумевает возможность реализации одного и того же шоколада (продукции) с различными потребительскими свойствами в России или в европейских странах.

В большинстве случаев функционирование системы прослеживаемости осуществляется на основе национальной системы цифровой маркировки и прослеживаемости товаров Центра развития перспективных технологий, созданного для реализации глобальных проектов в цифровой экономике «Честный ЗНАК». Основной задачей данной системы является гарантия потребителям подлинности и заявленного качества приобретаемой продукции [7].

Информация о предметах торговли хранится в базе данных ГС1 РУС в виде таблиц с наборами полей. Каждое поле представляет собой атрибут. Под атрибутами понимаются характеристики, используемые для описания всех характерных признаков предмета торговли. Этапу разработки предлагаемых атрибутов шоколада предшествует сравнительный анализ обязательных к заполнению атрибутов (существуют также опциональные), представленных в каталоге маркированного товара, на примере уже внедренной системы в отношении предметов одежды из натурального меха, обувных товаров и лекарственных препаратов [8; 9; 10].

Из проведенного анализа можно сделать вывод, что в отношении различных товарных групп количество и перечень обязательных атрибутов отличаются. Условно их можно разделить на общие - установленные для всех товаров и специфические - отражающие особенности отдельных товаров.

Общими для всех рассматриваемых групп товаров являются такие атрибуты как наименование товара на этикетке, бренд (торговая марка), 10-значный код ТН ВЭД, штрих-код/GTIN и дата публикации (план). Обратим внимание на наименование товара на этикетке, которое для лекарственных препаратов будет включать торговое наименование лекарственного препарата, форму лекарственного препарата и дозировку [10]; для предметов одежды из натурального меха и обувных товаров оно подразумевает наименование изделия, которое отображает все отличительные характеристики, по которым потребитель может отличить одно изделие от другого. При этом допускаются сокращения в его указании [8; 9]. В отношении предметов одежды из натурального меха также следует указывать полное наименование товара, т.е. полное наименование изделия без сокращений, содержащее отделки, комбинированные материалы, а также комплектующие изделия (ремни, митенки, съемные детали - воротники и т.п., 
Таблица 1. Перечень обязательных общих и специфических атрибутов, планируемых к указанию в каталоге маркированного товара, для шоколада в рамках системы цифровой маркировки и прослеживаемости товаров

\begin{tabular}{|c|c|c|c|}
\hline \multirow{2}{*}{ № $\mathbf{n} / \mathbf{n}$} & \multicolumn{3}{|c|}{ Наименование обязательных к заполнению атрибутов } \\
\hline & Общие атрибуты & № $\Pi / \Pi$ & Специфические атрибуты \\
\hline 1 & Полное наименование товара & 10 & Страна происхождения и регион произрастания какао-бобов \\
\hline 2 & Наименование товара на этикетке & 11 & Сорт какао-бобов \\
\hline 3 & $\begin{array}{l}\text { Наименование страны- } \\
\text { изготовителя }\end{array}$ & 12 & Состав шоколадной части \\
\hline 4 & $\begin{array}{l}\text { Наименование компании- } \\
\text { изготовителя }\end{array}$ & 13 & Наличие заменителя (заменителей) в шоколадной части \\
\hline 5 & Бренд (торговая марка) & 14 & $\begin{array}{l}\text { Характер заменителя (заменителей) в шоколадной части, содержание } \\
\text { заменителя (заменителей) к общему весу шоколадной массы (\%) (при } \\
\text { его (их) наличии) }\end{array}$ \\
\hline 6 & 10-значный код ТН ВЭД & 15 & Состав начинки (для шоколада с начинкой) \\
\hline 7 & Масса нетто (г) & 16 & Характер добавлений (для шоколада с добавлениями) \\
\hline 8 & Штрих-код/GTIN & 17 & $\begin{array}{l}\text { Содержание масла какао, общего сухого остатка какао-продуктов, } \\
\text { сухого обезжиренного остатка какао-продуктов, сухих веществ молока } \\
\text { и (или) продуктов его переработки, молочного жира и общего жира } \\
\text { в шоколадной массе (\%) }\end{array}$ \\
\hline 9 & Дата публикации (план) & & \\
\hline
\end{tabular}

не указывать модель, цвет, размер и пр.) [8]. Из вышеописанного следует, что основным назначением любого наименования товара, приводимого в атрибуте, и подробного перечисления его признаков (например, вида обуви, материала верха, материала подкладки и материала низа) является содействие потребителю при выборе продукции в соответствии с его потребностями и ожиданиями.

Наибольшее количество атрибутов характерно для лекарственных препаратов. Они также включают представление сведений о первичной и вторичной видах упаковок и информацию о регистрационном удостоверении. Для предметов одежды из натурального меха ключевую роль будут играть страна происхождения, размер изделия, вид меха, наличие (отсутствие) крашения меха, модель, цвет и др. отличительные признаки.

Выявление специфических для шоколада атрибутов, предлагаемых в рамках системы цифровой маркировки и прослеживаемости товаров, проводилось также с учетом современных тенденций мировых лидеров-производителей высококачественного какао-сырья и готовой продукции. Так, например, ассоциация швейцарских производителей шоколада «CHOCOSUISSE» [11] использует систему цифровой маркировки и прослеживаемости товаров в отношении какао-бобов - от плантации до фабрики, учитывая страну происхождения, регион произрастания какао-бобов и их сорт.

На основе изученных сведений о системе цифровой маркировки и прослеживаемости товаров и наблюдае- мых тенденциях на рынке сырья и готовой продукции разработан и предложен перечень обязательных общих и специфических атрибутов, планируемых к указанию в каталоге маркированного товара, в случае распространения цифровой маркировки на шоколад. Согласно вышеуказанному, одним из основных общих атрибутов для всех видов продукции является «наименование», в котором должны быть отражены не только видовое наименование продукции, но и признаки, характеризующие разновидность товара. Таким образом, для шоколада помимо видового наименования продукции (шоколад, шоколад с начинкой, шоколад с добавлениями, кондитерская плитка и т.д.) необходимы к указанию будут признаки, отражающие разновидность шоколада (молочный, темный, горький, белый и т.д.) (таблица 1).

Из таблицы № 1 следует, что атрибуты № 1-9 являются общими. Для представления более полной информации о шоколаде к ранее разработанным для других групп товаров характеристикам дополнительно следует указывать обязательные сведения о стране-изготовителе готовой продукции и массе нетто (г). Отметим, что как полное, так и наименование товара на этикетке формируются исходя из специфических атрибутов № 10-17, указанных в таблице № 1 .

Характеристиками, определяющими основные потребительские свойства шоколада (специфические атрибуты), являются следующие:

1. Страна происхождения и регион произрастания какао-бобов (№ 10). Сорт какао-бобов (№ 11). 
Таблица 2. Общие и специфические атрибуты, обязательные к представлению в каталоге маркированного товара в рамках системы цифровой маркировки и прослеживаемости товаров для импортного товара: «Шоколад темный с цельным обжаренным орехом лещины» [13; 14$].$

\begin{tabular}{|c|c|c|}
\hline \multirow[t]{2}{*}{ № п/п } & Наименование обязательных к заполнению атрибутов & $\begin{array}{l}\text { Товар «Шоколад темный с цельным обжаренным } \\
\text { орехом лещины» }\end{array}$ \\
\hline & \multicolumn{2}{|l|}{ Общие атрибуты } \\
\hline 1 & Полное наименование товара & $\begin{array}{l}\text { Шоколад темный с цельным обжаренным орехом } \\
\text { лещины }\end{array}$ \\
\hline 2 & Наименование товара на этикетке & $\begin{array}{l}\text { Шоколад темный с цельным обжаренным орехом } \\
\text { лещины }\end{array}$ \\
\hline 3 & Наименование страны-изготовителя & Германия \\
\hline 4 & Наименование компании-изготовителя & Альфред Риттер ГмбХ \& Ко. КГ \\
\hline 5 & Бренд (торговая марка) & Ritter Sport \\
\hline 6 & 10-значный код ТН ВЭД & 1806321000 \\
\hline 7 & Масса нетто (г) & 100 \\
\hline 8 & Штрих-код/GTIN & 4000417702005 \\
\hline 9 & Дата публикации (план) & 10.11 .2020 \\
\hline \multicolumn{3}{|c|}{ Специфические атрибуты } \\
\hline 10 & Страна происхождения и регион произрастания какао-бобов & См. примечание \\
\hline 11 & Сорт какао-бобов & См. примечание \\
\hline 12 & Состав шоколадной части & $\begin{array}{l}\text { Сахар, какао тертое, масло какао, эмульгатор (соевый } \\
\text { лецитин) }\end{array}$ \\
\hline 13 & Наличие заменителя (заменителей) в шоколадной части & Отсутствуют \\
\hline 14 & $\begin{array}{l}\text { Характер заменителя (заменителей) в шоколадной части, } \\
\text { содержание заменителя (заменителей) к общему весу } \\
\text { шоколадной массы (\%) (при его (их) наличии) }\end{array}$ & Отсутствуют \\
\hline 15 & Состав начинки (для шоколада с начинкой) & Отсутствует \\
\hline 16 & Характер добавлений (для шоколада с добавлениями) & Ядро ореха лещины (крупные добавления) \\
\hline 17 & $\begin{array}{l}\text { Содержание масла какао, общего сухого остатка какао- } \\
\text { продуктов в шоколадной массе (\%) } \\
\text { * остальные показатели в отношении темного шоколада } \\
\text { не нормируются в нормативных документах }\end{array}$ & $\begin{array}{l}\text { Содержание масла какао - см. примечание } \\
\text { Общий сухой остаток какао-продуктов - не менее 50\% }\end{array}$ \\
\hline
\end{tabular}

Примечание. Атрибут заполняется на основе сведений, представленных производителем.

В настоящее время на выпускаемой продукции данные сведения отсутствуют.

Страна происхождения и регион произрастания какао-бобов имеют центральное значение, так как именно климатические условия, в которых выращивается какао-дерево, формируют органолептические показатели шоколада. Также сведения, представленные в данных показателях, оказывают большое влияние на стоимость какао-бобов и на шоколад как готовый вид продукции.

2. Состав шоколадной части (№ 12). Наличие заменителя (заменителей) в шоколадной части (№ 13). Характер заменителя (заменителей) в шоколадной части, содержание заменителя (заменителей) к общему весу шоколадной массы (\%) (при его (их) наличии) (№ 14). Состав начинки (для шоколада с начинкой) (№ 15). Характер добавлений (для шоколада с добавлениями) (№ 16).

Данные качественные показатели являются основными, с одной стороны, для формирования полного наименования товара и наименование товара на этикетке, с другой стороны,-для определения, например, органолептических свойств шоколада.

Тенденции, наблюдаемые на рынке растительных масел (т.е. активное использование при производстве шоколада не только масла какао, но и пальмового масла и его производных, рапсового, кокосового, масла ши и др.), являются в некоторой степени причиной неверного определения изготовителями видового наименования товара, что обуславливают необходимость обозначения наличия заменителя (заменителей) в шоколадной части (№ 13), его (их) характера (№ 14) и процентного содержания (№ 14) как отдельных атрибутов. Это позволит сформировать правильное и четкое представление о видовом наименовании товара и его качестве. Полученные при приобретении товара и считывании средств идентификации сведения позволят заблаговремен- 
но уведомить потребителя, что товар возможно имеет «салистое» послевкусие, ярко выраженный запах растительных масел, маслянистую консистенцию и неоднородную структуру. Степень «восприятия» заменителей зависит от их количества, однако даже разрешенный уровень (не более 5\% добавленных растительных жиров, отличных от масла какао, от общего веса готового продукта) [12] отражается на потребительских свойствах шоколада, что, соответственно, повлечет за собой изменение такого атрибута как «наименование товара».

3. Содержание масла какао, общего сухого остатка какао-продуктов, сухого обезжиренного остатка какао-продуктов, сухих веществ молока и (или) продуктов его переработки, молочного жира и общего жира в шоколадной массе (\%) (№ 17).

Данные атрибуты отражают различные физико-химические показатели шоколада и начинки, необходимость определение которых зависит от вида шоколада. Характеристики приводятся в соответствии с пищевым международным стандартом «Кодекс Алиментариус. Стандарт для шоколада и шоколадных изделий (CODEX STAN87-1981, Revю 1-2003)» [12] и ГОСТ 31721-2012 «Шоколад. Общие технические условия» [13], так как технический регламент Евразийского экономического союза на кондитерские изделия не разработан. Указание тех или иных показателей зависит от вида шоколада в соответствии с нормативными документами. Например, для белого шоколада массовые доли масла какао - не менее $20 \%$, молочного жира - 2,5-3,5\%, общего сухого остатка веществ молока и (или) продуктов его переработки - не менее $14 \%$ [12].

Рассмотрим примеры указания общих и специфических атрибутов, обязательных к представлению в каталоге маркированного товара, в рамках системы цифровой маркировки и прослеживаемости товаров в отношении шоколада (таблица 2).

Из таблицы видно, что полное видовое наименование продукции совпадает с наименованием товара на этикетке и соответствует составу шоколадной части, описанному в атрибутах. В отношении показателей № 10, № 11 и № 17 (содержание масла какао) не представляется возможным указать достоверные сведения, так как данные атрибуты заполняются на основе сведений, представленных производителем. В настоящее время на выпускаемой продукции данные сведения отсутствуют. В рассматриваемом образце отсутствуют заменители в шоколадной части, отсутствует начинка, но присутствуют крупные добавления в виде ядра ореха лещины. Содержание общего сухого остатка ка- као-продуктов указано верно, исходя из наименования продукции и её состава.

Распространение системы цифровой маркировки и прослеживаемости товаров на шоколад позволит, в т.ч. исключить присутствие на российском рынке такой продукции как, например, «Nelly», которая в настоящее время существует на рынке с таким наименованием продукции в маркировке как «Изделия кондитерские: Молочный шоколад с молочной начинкой «Nelly», но в составе содержит заменители масла какао. Экспертиза жирно-кислотного состава данного товара, проведенная ранее в рамках выпускной квалификационной работы, показала, что в шоколадной части присутствует частично гидрогенизированное пальмовое масло. Атрибуты № 1, № 2 и № 14 в рамках системы цифровой маркировки и прослеживаемости шоколада выглядели бы следующим образом:

№ 1 и № 2: Изделия кондитерские: Кондитерская плитка с начинкой«Nelly».

№ 14: Частично гидрогенизированное пальмовое масло. Содержание заменителя (заменителей) к общему весу шоколадной массы (\%) - атрибут заполняется на основе сведений, представленных производителем. В настоящее время на выпускаемой продукции данные сведения отсутствуют.

В случае указания атрибутов как было представлено выше они не противоречат низким потребительским свойствам товара, которые также были установлены в процессе органолептического анализа образца ранее (вкус несвойственный шоколаду, с посторонним «салистым» «жирным» привкусом, неисчезающим длительное время. Не ярко выраженный молочный привкус; запах несвойственный какао продуктам, присутствует слабый запах молока).

Предлагаемый перечень атрибутов при дальнейших исследованиях данной темы может быть расширен и скорректирован с учетом изменений мировых тенденций и развития цифровых технологий.

Дальнейшее совершенствование системы цифровой маркировки и прослеживаемости товаров, заключающееся в применении в отношении шоколада предложенных в рамках данной работы общих и специфических атрибутов, обязательных к представлению в каталоге маркированного товара, выделенных на основе анализа его свойств и характеристик, позволит, с одной стороны, сделать потребителю грамотный выбор товара, который соответствует его потребностям и ожиданиям, а с другой - обеспечит производителям конкурентное преимущество на рынке. 


\section{ЛИТЕРАТУРА}

1. Распоряжение Правительства Российской Федерации от 28.04.2018 № 792-р «0б утверждении перечня отдельных товаров, подлежащих обязательной маркировке средствами идентификации».

2. Шоколадный шок. URL: https://expert.ru/2016/01/19/shokoladnyij-shok/ (дата обращения: 01.10.2021).

3. Медведев 0.С., Медведева Н.А. Современные представления о возможном влиянии пальмового масла на здоровье человека // Вопросы питания. Том 85. № 1. 2016. С. 5-18.

4. Мелик-Касумов Т.Б., Рудниченко Ю.А., Кузнецова Т.Е., Кондрашова С.Б. и др. Экспериментальная оценка влияния пальмового масла на процессы регуляции физиологических функций организма // Вопросы питания. Приложение. Том 87. № 5. 2018. С. 35-36.

5. Технический регламент Евразийского экономического союза 022/2011 «Пищевая продукция в части ее маркировки». URL: http://docs.cntd.ru/ document/902320347 (дата обращения: 15.09.2021).

6. ФАС возбудила дело из-за качества швейцарского шоколада. Российская газета. URL: https://rg.ru/2020/08/25/fas-v0zbudila-delo-iz-zanekachestvennogo-shvejcarskogo-shokolada.html (дата обращения: 15.09.2021).

7. Официальный сайт Национальной системы маркировки «Честный 3HAK». URL: https://честныйзнак.pф/0-chestnom-znake/nacionalnaya-sistemamarkirovki/ (дата обращения: 15.09.2021).

8. Руководство по работе с продукцией в Системе GS46 - предметы одежды из натурального меха. URL: http://www.gs1ru.org/wp-content/ uploads/2018/07/GS1_Руководств0-GS46_Меховые-изделия_red-1_4.pdf. (дата обращения: 20.09.2021).

9. Руководство по работе с продукцией в Системе GS46 - Обувь. URL: http://www.gs1ru.org/wp-content/uploads/2018/07/GS1_Руководств0-по-раб0те-с-продукцией-в-системе-GS46-0бувь.pdf (дата обращения: 20.09.2021).

10. Руководство по работе с продукцией в Системе GS46 - мониторинг движения лекарственных препаратов. URL: http://www.gs1ru.org/wp-content/ uploads/2017/06/GS1_Руководств0-GS46_Мониторинг-движения-ЛП.рdf (дата обращения: 20.09.2021).

11. Ассоциация швейцарских производителей шоколада «CHOCOSUISSE». URL: https://www.chocosuisse.ch/en/subjects/sustainability/ (дата обращения: 20.09.2021).

12. Кодекс Алиментариус. Стандарт для шоколада и шоколадных изделий (CODEX STAN87-1981, Revю 1-2003). URL: https://base.garant.ru/70192944/ (дата обращения: 20.09.2021).

13. ГОСТ 31721-2012 «Шоколад. Общие технические условия». URL: http://docs.cntd.ru/document/gost-31721-2012 (дата 0бращения: 20.09.2021).

14. Официальный сайт какао шоколада «Ritter Sport». URL: https://www.ritter-sport.de/ru/unser_kakao/ (дата обращения: 20.09.2021).

() Петросян Анна Эдиковна ( talismananna96@mail.ru).

Журнал «Современная наука: актуальные проблемы теории и практики» 